\title{
La unión de hecho en el Perú, los derechos de sus integrantes y desafíos pendientes $\left({ }^{*}\right)\left({ }^{* *}\right)$
}

\section{The common law marriage in Peru, the rights of its members and pending challenges}

\author{
Erika Irene Zuta Vidal(***) \\ Pontificia Universidad Católica del Perú
}

\begin{abstract}
Resumen: En este artículo se analiza la regulación de las uniones de hecho en el Perú desde sus inicios hasta la actualidad. Se enfoca en su evolución, desde el nulo reconocimiento de derechos e incluso vulneración de los derechos fundamentales de los hijos nacidos dentro de una convivencia, hasta su regulación constitucional y la consagración del principio de igualdad. Se parte de considerar a las uniones de hecho como fuente de familia y se examinan los elementos más importantes de las mismas, los derechos que los concubinos han ido adquiriendo, ya sea normativamente como a nivel jurisprudencial, así como también, se abordan los desafíos pendientes.
\end{abstract}

Palabras clave: Unión de hecho - Concubinato - Matrimonio - Familia

\begin{abstract}
This article analyzes the regulation of common law marriage in Peru from its beginnings to the present. It focuses on its evolution, from a null recognition of rights and even violation of the fundamental rights of children born within a cohabitation, to its constitutional regulation and the consecration of the principle of equality. Starting from considering common law marriage as a source of family and examining its most important elements, the rights that concubines have been acquiring, either normatively or at a jurisprudential level, as well as addressing pending challenges.
\end{abstract}

Keywords: Common law marriage - Concubinage - Marriage- Family

Sumario: 1. Introducción_2. Antecedentes_3. Naturaleza jurídica de la unión de hecho_4. Requisitos que configuran la unión de hecho_5. Posesión constante

${ }^{*}$ *) Nota del editor: Este artículo fue recibido el 11 de diciembre de 2017 y su publicación fue aprobada el 25 de junio del 2018.

$\left.{ }^{* *}\right)$ Documento elaborado en base al artículo publicado en la Revista Pólemos: http://polemos.pe/el-reconocimiento-de-derechosa-los-integrantes-de-las-uniones-de-hecho/.

${ }^{* * *}$ Docente del curso de Derecho de Familia y Derecho de Sucesiones de la Facultad de Derecho de la Pontificia Universidad Católica del Perú. Magíster en Gerencia Social, Abogada y egresada de la Facultad de Educación para el Desarrollo de la Pontificia Universidad Católica del Perú. 
La unión de hecho en el Perú, los derechos de sus integrantes y desafíos pendientes The common law marriage in Peru, the rights of its members and pending challenges

de estado_6. Formas de reconocer la unión de hecho_7. Derechos reconocidos a las uniones de hecho_8. Filiación Extramatrimonial_9. Disolución de la unión de hecho_10.Unión de hechohomoafectivas_11. Conclusiones_12. Referencias bibliográficas

\section{Introducción}

Durante mucho tiempo en nuestra conservadora sociedad, el concubinato fue cuestionado, señalado con menoscabo y tratado de manera infame, debido a prejuicios vinculados a una concepción tradicional de familia vinculada exclusivamente al matrimonio y a cánones religiosos. No obstante, esta forma de familia siempre ha existido, incluso antes de la existencia del matrimonio, aunque legalmente no tuvieran un reconocimiento. Esta situación conllevó a que sus integrantes no gozaran de los derechos y obligaciones similares a los cónyuges y que incluso los hijos, producto de aquellas relaciones de pareja, sean denominados hijos ilegítimos.

Es recién con la Constitución de 1979 que las uniones de hecho gozan de reconocimiento normativo, asimismo, estipula que todos los hijos tienen iguales derechos y queda prohibida toda mención sobre el estado civil de los padres y la naturaleza de la filiación de los hijos en los registros civiles y en cualquier documento de identidad y consagra la igualdad entre hombres y mujeres con la consiguiente igualdad en las relaciones familiares.

En ese mismo contexto, nuestra actual Carta Magna, en su artículo 5, define a la unión de hecho como: "La unión estable de un varón y una mujer, libres de impedimento matrimonial, que forman un hogar de hecho, da lugar a una comunidad de bienes sujeta al régimen de la sociedad de gananciales en cuanto sea aplicable". El artículo 4 de la misma explicita que la comunidad y el Estado detentan la obligación de proteger a la familia y promover el matrimonio, entendiendo que la familia no está asociada únicamente al matrimonio y que el concubinato es también una fuente generadora de familia amparada por nuestro ordenamiento y veremos cómo, progresivamente, sus integrantes han ido ganando mayores derechos.

Esta regulación constitucional es inherente a una realidad en el cual la convivencia va en aumento y el matrimonio va decreciendo, ya sea porque las parejas optan por no contraer matrimonio, porque no cuentan con los medios económicos o porque es un proyecto que ha sido postergado. Así tenemos que, según el INEI, en el año 2004, el 17.6\% manifestó que su estado civil era conviviente y en el año 2013 , lo hizo un $20.4 \%$. Por otro lado, en el año 2004 , el $30.8 \%$ señaló que su estado civil era casado y en el año 2013 , lo hizo un $28.1 \%{ }^{(1)}$.

A continuación, se detallarán algunas consideraciones importantes sobre esta institución familiar, partiremos de los antecedentes y su naturaleza jurídica, para luego abordar, los requisitos, la posesión constante de estado, las formas de su reconocimiento, los derechos ganados por los concubinos, la filiación extramatrimonial, su disolución y finalmente, las uniones homoafectivas.

\section{Antecedentes}

En nuestro país, el Código Civil de 1852 hizo referencia, exclusivamente, al concubinato como causal de separación de los cónyuges y no reguló las uniones de hecho porque tuvo una marcada influencia del Derecho Canónico en lo referido al matrimonio. Lo cual tiene asidero en la Carta Política de 1839, vigente en esa época, que en su artículo 3 refería "su religión es católica, apostólica y romana, que profesa sin permitir el ejercicio de cualquier otro culto". El matrimonio religioso era el único reconocido y que legitimaba a la familia, toda relación fuera de ella merecía el rechazo de la sociedad (Varsi 2011, 388).

Si bien con la dación del Código Civil de 1936 estaba vigente la Constitución de 1933 en la cual hubo un notable avance en cuanto a la incorporación de garantías individuales, se reconoció la libertad de conciencia y de creencia y no existió norma expresa respecto

(1) INEI, Instituto Nacional de Estadística e Informática, “Estado de la Población Peruana 2014”,https://www.inei.gob.pe/media/ MenuRecursivo/publicaciones_digitales/Est/Lib1157/libro.pdf 
a la Iglesia Católica, aunque, la influencia de la Iglesia seguía siendo significativa y, por lo tanto, se propició una posición conservadora de la institución matrimonial frente a la unión de hecho. Es así que este Código solo la mencionó a propósito del tratamiento de los hijos en los casos de la investigación judicial de paternidad y en cuanto a los derechos sucesorios de los hijos legítimos e ilegítimos, otorgándoles más derechos a los hijos legítimos si heredaban conjuntamente con hijos ilegítimos (Varsi 2011, 388-393).

La Ley 13157 del año 1961, Ley de Barrios Marginales o Barriadas señalaba que cuando el adquirente de un lote marginal que no esté casado y no tenga impedimento de casarse, lo ocupe con una mujer con la cual hace vida marital, el bien será de ambos para lo cual se expedirá el título a nombre de los dos. Posteriormente, la Ley 17716 - Ley de Reforma Agraria de 1969 estipulaba como beneficiaria de la adjudicación gratuita de la unidad familiar a la compañera permanente, en caso muriera el adjudicatario falleciera sin haberla cancelado. (Reinoso 1987, 57) En 1970, el Tribunal Agrario reconoce el derecho de la concubina en la adquisición de predios rústicos adquiridos durante la convivencia, pero vinculándolo al enriquecimiento ilícito (Aguilar 2016, 151).

El Decreto Ley 29598 de 1974 - Empresas de propiedad social estipulaba que los certificados de retiro serán transferidos a la conviviente que mantiene estado de permanente compañera del causante y siempre que se encuentre registrada en la ficha del trabajador (Reinoso 1987, 57).

Adicionalmente, las Leyes 8439 y 8569 permitieron que la concubina reciba la compensación por tiempo de servicios de su conviviente y trabajador fallecido. Pero todo esto era insuficiente, ya que al no estar las uniones de hecho reguladas legalmente se generaban situaciones de injusticia, sobre todo cuando esta unión de hecho terminaba por decisión unilateral y la persona abandonada no tenía derechos reconocidos, ni entidad a dónde acudir y quedaba en desamparo total (Aguilar 2016, 151-152).

Es así que paulatinamente se va abriendo camino para la incorporación de las uniones de hecho a nivel constitucional.

\section{Naturaleza jurídica de la unión de hecho}

A nivel doctrinal se plantean tres teorías para establecer la naturaleza jurídica de la unión de hecho: a) Teoría institucionalista; Partimos en reconocer que el matrimonio es una institución, en ese sentido, a la unión de hecho le correspondería una naturaleza jurídica similar, en razón de que es un acuerdo de voluntades y cumple los elementos propios del matrimonio, como son los deberes de cohabitación, fidelidad y asistencia, generando consecuencias jurídicas. Esta teoría es la más aceptada y considera que la unión de hecho al ser fuente de familia debe ser considerada como una institución.

b) Teoría contractualista; La unión de hecho se presenta como una relación exclusivamente contractual, siendo el factor económico el sustento de la existencia de las relaciones convivenciales. Al igual que en el matrimonio, las razones por las cuales una pareja decide convivir no se ciñen al tema económico, sino que existen aspectos personales que trascienden las obligaciones propias al deber de asistencia y ayuda mutua.

c) Teoría del acto jurídico familiar; Esta teoría pone énfasis en la voluntad de sus integrantes en generar relaciones familiares. El Tribunal Constitucional ha señalado que se "está ante una institución que se fundamenta en la autonomía de la voluntad de quienes la integran y que en puridad se caracteriza por su informalidad en cuanto a su inicio y su desarrollo" (Plácido 2011, 386-387).

\section{Requisitos que configuran la unión de hecho}

Es relevante precisar que no todas las relaciones de convivencia están protegidas por nuestro ordenamiento, así el artículo 326 de nuestro Código Civil y la jurisprudencia han establecido una serie de requisitos, entre los cuales podemos indicar los siguientes: 
La unión de hecho en el Perú, los derechos de sus integrantes y desafíos pendientes The common law marriage in Peru, the rights of its members and pending challenges

a) Unión estable entre un varón y una mujer; es decir, debe ser una pareja heterosexual que conviva, que tenga intimidad y vida sexual, para alcanzar finalidades y cumplir deberes semejantes a los del matrimonio. Se equipara la unión de hecho al matrimonio. En ese sentido, nos remitimos a lo regulado en los artículos 288 y 289 del Código Civil y establecemos que son deberes que nacen del matrimonio y de las uniones de hecho: el deber de fidelidad, de asistencia, de cohabitación y respecto a los hijos, tienen el deber de alimentarlos y educarlos.

Una de las finalidades del matrimonio y también de la unión de hecho es hacer vida en común para lo cual, se debe establecer un domicilio conyugal o convivencial, según sea el caso. En las relaciones matrimoniales, cuando se rompe este deber pueden ocurrir distintas consecuencias: que el matrimonio continúe vigente a pesar que ya no viven juntos o que debido a este alejamiento, se inicie un proceso de separación legal o divorcio por mutuo acuerdo o por las causales de separación de hecho o abandono injustificado del hogar conyugal. En el caso de las uniones convivenciales, esta separación física da lugar a la culminación de la unión de hecho.

Otro de los deberes, es la fidelidad, que va de la mano con el que la unión de hecho sea monogámica. En las relaciones matrimoniales, el incumplimiento de este deber puede dar lugar a causales de divorcio o separación de hecho, como son el adulterio, la homosexualidad o la conducta deshonrosa. En el caso de las uniones de hecho, el conviviente ofendido puede optar por dar por concluida la convivencia o por perdonar la infidelidad y continuar la relación. El deber de asistencia será desarrollado más adelante a propósito del tema de los alimentos entre convivientes.

Respecto a los hijos, existe el deber de alimentarlos y educarlos lo cual viene ligado a la figura de la patria potestad, independiente de la relación que tuvieron los padres.

Es preciso agregar que también se reconoce la igualdad del hombre y la mujer en el gobierno del hogar, con lo cual desaparece la potestad marital por lo menos en el plano normativo, en consecuencia, debemos apuntar a la conformación de familias democráticas. b) Voluntariamente realizada, sin coacción; No cabe pues, una convivencia producida por retención violenta o rapto.

c) Libres de impedimento matrimonial; es decir, no deben estar incursos en los impedimentos matrimoniales regulados en los artículos 241, 242 y 243 del Código Civil, algunos de los cuales son: estar casado, ser menor de edad, adolecer de alguna enfermedad crónica, contagiosa y transmisible por herencia, ser parientes consanguíneos en línea recta o colateral en segundo y tercer grado, los afines en línea recta, entre otros. Con lo cual la relación de convivencia de una persona casada con otra distinta a su cónyuge no está protegida por nuestro ordenamiento y es considerada como unión de hecho impropia y si alguno de los integrantes resultara perjudicado económicamente solo cabría interponer una demanda por enriquecimiento indebido.

d) Permanente; dado que debe durar por lo menos dos años continuos, por lo tanto, los plazos de convivencia intermitentes no se suman. Asimismo, es necesario precisar que el plazo se empieza a contabilizar desde que los concubinos estén libres de impedimento matrimonial, de tal forma que, en el caso que una pareja conviva y uno de ellos aún esté casado, el plazo se computará desde el momento que esté divorciado por más que la convivencia haya sido anterior.

e) Exclusiva; es decir, monogámica y no será considerada aquella relación en donde convivan y se mantengan relaciones sexuales con más de una persona debido a que no está contemplado el reconocimiento de dos o más concubinatos simultáneos.

f) Notoriedad; la relación de convivencia tiene que ser pública y exteriorizada ante 
Erika Irene Zuta Vidal

terceros quienes pueden ser familiares, amigos, conocidos y/o vecinos.

\section{Posesión constante de estado}

El segundo párrafo del artículo 326 del Código Civil indica que la posesión constante de estado debe probarse con cualquiera de los medios admitidos por la ley procesal, siempre que exista un principio de prueba escrita. Enrique Varsi desarrolla los tres elementos que se requieren para que se configure la posesión de estado en el caso de las uniones de hecho:

- Trato (tractus); Es la forma en la cual una persona tiende a tratar a otra, pero para que tenga los efectos y consecuencias legales, este trato debe exteriorizarse, es decir debe ser notoria frente a terceros.

- $\quad$ Nombre (nomem propio); Elemento que implica identidad. Es la manera como se conocen y reconocen, por ejemplo, es la pareja de tal.

- Fama (fama correlata); Es la identificación y la legitimación social que realiza la comunidad a ese estado de familia convivencial.

Sin embargo, "la doctrina y la jurisprudencia moderna han prescindido de la exigencia conjunta de los tres elementos" y se señala que el trato es elemento revelador de la posesión de estado, aunque no hubiera exteriorización ni uso del apellido (Varsi 2011, 424-425).

Se ha indicado que el artículo 326 refiere que para probar la unión de hecho es necesaria la prueba escrita. Coincidimos con Alex Plácido cuando advierte que "esta última exigencia resulta excesiva si se considera la dificultad de contar con documentos escritos, en una relación familiar que se caracteriza por la oralidad o por la simple concurrencia de circunstancias de comportamiento que revelan su existencia; siendo, precisamente, la prueba testimonial la que asume mayor relevancia en asuntos de derecho de familia. Por ello, debería eliminarse tal requerimiento"(Plácido 2001, 257).

\section{Formas de reconocer la unión de hecho}

En los últimos años a los convivientes se les ha reconocido no solo derechos patrimoniales sino también derechos personales, lo cual se ha dado no solo a nivel legislativo sino también jurisprudencial. Para que una unión de hecho goce de la totalidad de derechos reconocidos es imperioso e ineludible que esta sea declarada judicialmente o que se encuentre inscrita en el Registro Personal de Registros Públicos (Artículo 39 de la Ley 26662 y Ley 29560). A continuación, explicaremos ambas opciones:

\subsection{A nivel judicial}

El proceso judicial de reconocimiento de unión de hecho se inicia, en la mayoría de los casos, cuando uno de los convivientes fallece o debido a la decisión unilateral de uno de sus integrantes de dar por concluida la convivencia.

Algunos de los problemas al acudir a esta vía son las pruebas y la duración del juicio, ya que estamos ante un proceso de conocimiento, por lo cual lo más recomendable es que en un mismo juicio se plantee como pretensión principal el reconocimiento de la unión de hecho y como pretensión accesoria, la liquidación de los gananciales. Asimismo, debe quedar establecido, de manera fehaciente, el inicio y la culminación de la unión de hecho a fin de hacer un adecuado reparto de los gananciales si los hubiere.

Coincidimos con el profesor Benjamín Aguilar en que la sentencia de reconocimiento de unión de hecho es declarativa debido a que reconoce una situación de hecho pre existente y sus efectos se retrotraen al momento al inicio de la convivencia. "Si la sociedad de bienes se equipara a la sociedad de gananciales, y si ésta aparece con el matrimonio, entonces deberíamos concluir que igualmente la sociedad de bienes aparece cuando se inicia esta unión de hecho, y reconocido que sea el concubinato, entonces sus efectos deberían retrotraerse al comienzo del mismo". (Aguilar 2016, 157-158). 
La unión de hecho en el Perú, los derechos de sus integrantes y desafíos pendientes The common law marriage in Peru, the rights of its members and pending challenges

Es preciso agregar que la Casación 1532-2013-Lambayeque nos recuerda que el artículo 17 de la Convención América de Derechos Humanos establece que el derecho a fundar una familia es un derecho humano, lo cual está regulado de manera implícita en el artículo 5 de nuestra Constitución. En ese sentido, "la acción de reconocimiento de unión de hecho no está sujeta a plazo prescriptorio, pues los derechos humanos son por su propia naturaleza imprescriptibles, según la Convención de Viena".

\subsection{A nivel notarial}

Uno de los graves problemas que acarrea el goce de derechos para los convivientes es la acreditación de la unión de hecho, para lo cual la única vía posible era la judicial. Con la finalidad de contrarrestar esta dificultad, se dio la Ley $N^{\circ} 29560$ la cual otorga facultades a los notarios para tramitar el reconocimiento de unión de hecho.

La inscripción en el Registro Personal es un procedimiento no contencioso que requiere el consentimiento de ambos integrantes, que hayan convivido no menos de dos años continuos y debe contener la fecha de inicio de la convivencia. Se presenta una solicitud ante el notario, quien manda publicar un extracto de dicha solicitud en el Diario "El Peruano" y otro diario de amplia circulación. Transcurridos quince (15) días útiles desde la publicación del último aviso, sin que se hubiera formulado oposición, el notario extiende la escritura pública con la declaración del reconocimiento de la unión de hecho entre los convivientes y remite los partes al registro personal del lugar donde domicilian los solicitantes. En caso de oposición, el notario remite los actuados al Poder Judicial. Si los convivientes desean dejar constancia de haber concluido su estado de convivencia, podrán hacerlo en la escritura pública en la cual podrán liquidar el patrimonio social, para este caso no se necesita hacer publicaciones. El cese de la convivencia se inscribe en el Registro Personal.

Cabe agregar que encontramos un incremento en las inscripciones de las uniones de hecho ya que de enero a diciembre de 2016 se registraron 2,588 uniones de hecho en todo el país, en comparación, con el año 2015, cuando se inscribieron solo 673 uniones de hecho ${ }^{(2)}$. No obstante, aún existe mucho desconocimiento sobre el trámite para registrar la convivencia y los gastos a los cuales hay que incurrir pueden generar una barrera económica que limita el acceso a ella, por lo cual, todavía hay muchas parejas que no regularizan su unión.

Por otro lado, es trascendental que se reconozca a los concubinos como parientes por afinidad, adicionalmente, que se incorpore en el artículo 241 del Código Civil, como uno de los impedimentos absolutos del matrimonio a quienes tengan una relación de convivencia inscrita en el Registro Personal o declarada judicialmente. Lo cual debería encaminarse hacia la incorporación, dentro de los documentos requeridos para contraer matrimonio, el exigir a los contrayentes el Certificado Negativo de Unión de hecho, expedido por el registro personal de la oficina registral donde domicilian los solicitantes. Ello en vista de que al no existir el estado civil conviviente, el integrante de la unión de hecho sigue figurando en su Documento Nacional de Identidad (DNI) como soltero por lo cual, puede contraer matrimonio con una persona distinta a su conviviente aun estando inscrita su convivencia en el Registro Personal.

\section{Derechos reconocidos a las uniones de hecho}

Las uniones de hecho han ido ganando derechos, de manera progresiva, aunque cómo veremos hay muchos aspectos que merecen una mejor regulación y otros que aún están pendientes de ser tratados. A continuación, abordaremos algunos de estos derechos:

7.1. Reconocimiento de la sociedad de gananciales como régimen patrimonial Tanto la Constitución como el Código Civil regulan que la unión de hecho origina una

(2) SUNARP, Superintendencia Nacional de los Registros Públicos, https://www.sunarp.gob.pe/PRENSA/inicio/post/2017/02/17/ conoce-por-que-debes-inscribir-tu-convivencia-en-la-sunarp 
sociedad de bienes que se sujeta al régimen de sociedad de gananciales. Es decir, todos los bienes y deudas adquiridas durante la convivencia formarán parte del patrimonio social de ambos concubinos, entendiendo que se constituye la sociedad de gananciales desde el inicio de la convivencia y no desde que es declarada judicialmente o inscrita en el Registro Personal porque este reconocimiento es declarativo y no constitutivo. Por consiguiente, al concluir la unión de hecho también se liquida la sociedad de gananciales y los bienes sociales que hubieren adquirido deberán ser repartidos en partes iguales.

En base a lo anterior, debemos considerar que son aplicables algunas de las normas relativas a la sociedad de gananciales reguladas para el matrimonio y otras pueden ser impertinentes, por ejemplo el artículo 312 del Código Civil referido al derecho a contratar entre los cónyuges solo sobre los bienes propios o el 324 del Código Civil que establece la pérdida de gananciales por el cónyuge culpable de la separación de hecho, no son aplicables a la uniones convivenciales (Plácido 2001, 256).

Empero hay otras normas que si son aplicables como son las referidas a la diferenciación entre bienes propios y bienes sociales, el considerar que los frutos de los bienes propios son bienes sociales y que para disponer de los bienes sociales se requiere el asentimiento de ambos concubinos (artículo 315 del Código Civil) Sin embargo, una diferencia relevante en comparación con los cónyuges es que los convivientes no tienen la posibilidad legal de optar por el régimen de separación de patrimonios. Por tanto, "el régimen patrimonial de las uniones de hecho es único y forzoso" (Plácido 2001, 255).

Sin embargo, "a propósito de una sentencia del tribunal registral (...) logro inscribirse una separación de patrimonios de una unión de hecho, como es de verse de la Ficha N²1094 del Registro de Personas Naturales de esa oficina" (Aguilar 2017, 86). A pesar de esta resolución, nuestra normativa no lo permite; en consecuencia, consideramos que debería estar expresamente regulado la posibilidad de que las uniones de hecho pueden optar por el régimen económico de su preferencia.

\subsection{Alimentos entre concubinos}

El profesor Benjamín Aguilar puntualiza que "la importancia del derecho alimentario se traduce en el fin que persigue, que no es otro que cubrir un estado de necesidad en quien lo solicita, respondiendo a una de sus características, quizás la más trascendente, la de ser un derecho vital, un derecho de urgencia" (Aguilar 2016, 488).

De acuerdo a lo anterior, dentro de los integrantes de una familia debería ser natural el prestarse asistencia mutuamente pero, esta situación no siempre ocurre y por esta razón, en muchas situaciones se hace necesaria la intervención judicial. En el caso del matrimonio existe una obligación legal que hace que los cónyuges puedan demandar alimentos no solo durante la cohabitación sino también cuando no hay convivencia o en circunstancias especiales, incluso cuando ya están divorciados.

En el caso de las uniones de hecho nuestra legislación establece que deben cumplir deberes semejantes al matrimonio y si analizamos cuales son estos deberes nos encontramos con el deber de asistencia entre los cónyuges, el cual tiene como correlato el artículo 474 del Código Civil que refiere que se deben recíprocamente alimentos los cónyuges, no haciendo ninguna mención a los convivientes. De modo que para las uniones de hecho solo existe una obligación natural de prestar alimentos.

Tomando en cuenta lo anterior debería estar contemplado en nuestra normativa que los convivientes gocen del derecho y el deber de prestarse alimentos recíprocamente, pero esa situación no ocurre. Nuestro Código Civil estipula que la pensión de alimentos procede en caso de abandono injustificado de uno de los concubinos, es decir, para que se pueda gozar de esta pensión, la convivencia debe haber concluido no existiendo posibilidad que se le otorgue una pensión de alimentos a uno de los convivientes mientras esté vigente la unión de hecho, lo cual vulnera el deber de asistencia que debe existir entre los integrantes de las familias. 
La unión de hecho en el Perú, los derechos de sus integrantes y desafíos pendientes The common law marriage in Peru, the rights of its members and pending challenges

Es preciso agregar que el juez en caso de abandono unilateral de uno de los convivientes tiene la posibilidad de conceder, a elección del abandonado, una cantidad de dinero por concepto de indemnización o la pensión de alimentos.

La pensión de alimentos se debe fijar en proporción de las necesidades de quien los solicita y las posibilidades de quien debe darlos, asimismo, se debe tomar en cuenta el trabajo doméstico no remunerado realizado por alguno de los obligados. Finalmente, esta obligación cesará en caso de fallecimiento del obligado o del alimentista, si el/la alimentista contrae nupcias con otra persona, si el obligado disminuye sus ingresos y puede estar en peligro su propia subsistencia o si el estado de necesidad del/la alimentista desaparece.

\subsection{Derechos laborales y la pensión de viudez}

El autor Alex Plácido destaca que "en el Derecho Laboral, se reconoce que el conviviente supérstite tiene derecho al $50 \%$ del monto acumulado de la compensación por tiempo de servicios y sus intereses, que a solicitud le será entregado por el depositario, en caso de fallecimiento del trabajador compañero" (D.S. N ${ }^{\circ}$ 001-97-TR-TUO del Decreto Legislativo 650 , artículo 54). De otra parte, se admite que el conviviente se beneficiario del seguro de vida a cargo del empleador de su compañero trabajador (Decreto Legislativo $\mathrm{N}^{\circ} 688$, artículo 1) (Plácido 2001, 254).

Este mismo autor nos recuerda que en la legislación del "Sistema Privado de Administración de Fondos de Pensiones se establece que el conviviente tiene derecho a las pensiones de invalidez y sobrevivencia y es potencial beneficiario de la pensión de jubilación de su compañero (D.S. N 004-98EF- Reglamento del TUO del Ley del Sistema Privado de Administración de Fondo de pensiones, artículo 113) (Plácido 2001, 254).

A pesar de estas regulaciones específicas y que en el sistema privado de pensiones se reconozca la pensión de viudez, en el sistema público de pensiones no existe una norma que reconozca la pensión de viudez para los concubinos. Es más la Ley 19990 y la Ley 20530 omiten expresamente el derecho a la pensión de viudez reconociéndola solo para las uniones matrimoniales. Lo cual ha dado lugar a que jurisprudencialmente se haya desarrollado este tema y si bien, en un principio la pensión de viudez para la conviviente supérstite fue denegada por el Tribunal Constitucional, posteriormente, cambio su pronunciamiento reconociendo la pensión de viudez para la conviviente a pesar de no estar reconocida legislativamente. Veamos a continuación algunos casos:

En una primera sentencia del Tribunal Constitucional, referida al caso Anaya (EXP. $N^{\circ}$ 03605-2005-AA/TC) se denegó el derecho de pensión de viudez para una conviviente y se estableció que no se puede tratar en igualdad al matrimonio y la unión de hecho y así como no se puede obligar a alguien a casarse, tampoco se puede obligar a tener los efectos previsionales propios del matrimonio.

Corrigiendo el pronunciamiento del caso Anaya, el mismo Tribunal en una sentencia emitida a propósito del caso Rosas Domínguez (Sentencia del TC 06572-2006-PA/TC) se aparta de su decisión anterior y refiere que los integrantes de las uniones de hecho pueden gozar no solo de derechos patrimoniales sino también de derechos personales, como la pensión de viudez y que las pensiones tienen la calidad de bienes sociales porque sirven para el sostenimiento de la familia y en ese aspecto, estipula lo siguiente:

"(...) al haberse comportado los convivientes como cónyuges, al asumir finalidades, obligaciones y deberes semejantes a los del matrimonio, la conviviente habría adquirido el derecho a la pensión de viudez".

"Sin importar el tipo de familia ante la que se esté, esta será merecedora de protección frente a las injerencias que puedan surgir del Estado y de la sociedad. No podrá argumentarse, en consecuencia, que el Estado solo tutela a la familia matrimonial, tomando en cuenta que existen gran cantidad de familias extramatrimoniales. Es decir, se comprende que el instituto de familia trasciende al del matrimonio, 
Erika Irene Zuta Vidal

pudiendo darse la situación de que extinguido este persista aquella".

Esta sentencia también reconoce que se estaría vulnerando el derecho- principio de igualdad ya que no existe argumento objetivo y razonable para que en el sistema privado de pensiones si se permita otorgar una pensión de viudez a los convivientes y en el sistema nacional de pensiones ello no sea posible. Por consiguiente, a una misma situación se le da un trato diferenciado dado que la contingencia para ambos casos es la misma, la muerte del conviviente.

Por otro lado, este pronunciamiento es trascendental porque reconoce que la familia es un instituto ético - social que se encuentra inevitablemente a merced de los nuevos contextos sociales y que la unión de hecho genera una dinámica a partir de la cual se originan dependencias entre sus integrantes y que conciben no solo obligaciones patrimoniales sino también personales como el deber de asistencia mutua. Del mismo modo, se evidencia que si bien el único titular de la pensión es quien realiza los aportes; en el caso de la pensión de viudez, esta debe ser concebida como una garantía para velar por el mantenimiento de una vida acorde con el principio de dignidad de aquellos que, en razón de un vínculo familiar directo, dependían económicamente de parte de dicha pensión, como es el caso de la concubina viuda.

\subsection{Derechos sucesorios}

Uno de los sustentos para no reconocer derechos sucesorios a los convivientes era que se desalentaría a las parejas a optar por el matrimonio debido a que tendrían los mismos derechos que el/la cónyuge. Consideramos que debe ser decisión de cada pareja el optar por alguna de estas instituciones al momento de iniciar una vida en común, lo cual parte de su autonomía, de su derecho a la libertad, de su derecho a formar una familia y que esta goce de una protección legal.

La Ley 30007 (promulgada el 17 de abril de 2013) concede, por primera vez en nuestro país, derechos hereditarios a los convivientes. Esta norma regula la igualdad del concubino y el cónyuge en materia sucesoria, por consiguiente, constituye un heredero de tercer orden (816 CC) que puede heredar conjuntamente con los hijos o descendientes del causante o con sus progenitores o ascendientes, es asimismo, un heredero forzoso (724 CC) a quien no se le puede privar de la herencia a no ser por causales de indignidad o desheredación.
Sus derechos sucesorios forman parte de la "legítima" (aquella parte de la que no puede disponer) en consecuencia, no se debe exceder de la cuota de libre disponibilidad permitida, ya sea de la tercera parte cuando se tiene hijos y conviviente y de la mitad en caso se tenga padres y conviviente; asimismo, en caso de no haber hecho uso de la cuota de libre disponibilidad y si el concubino fallecido no tiene hijos o padres, el sobreviviente podrá heredar la totalidad el patrimonio dejado por el causante.

Adicionalmente, se le permite al conviviente supérstite, cuando concurra con otros herederos, seguir viviendo en el inmueble que fue su casa habitación cuando la suma de lo que le corresponde por gananciales y por cuota hereditaria no le alcance para adjudicarse el bien. Por lo tanto, tiene el derecho a gozar del derecho de habitación vitalicia y también, del derecho de usufructo en caso no estuviere en situación económica que le permita sostener los gastos de la casa habitación, el conviviente puede arrendar el inmueble aunque con autorización judicial. Se entiende que mientras esté afectado por los derechos de habitación o de usufructo, la casa habitación tendrá la condición legal de patrimonio familiar. Sin embargo, mientras ambos convivientes estén vivos, no pueden constituir, sobre sus bienes en común, patrimonio familiar sino solo lo pueden hacer los cónyuges. En el caso que no goce de algunos de estos derechos, el conviviente que concurra con otros herederos también puede optar por el usufructo de la tercera parte de la herencia, lo cual genera la indivisión del patrimonio hereditario hasta que se extinga este derecho.

Es preciso recordar que la legítima del integrante sobreviviente de la unión de hecho es independiente del derecho que le corresponde por gananciales.

Para que los concubinos puedan ejerces estos derechos sucesorios se exigen los siguientes requisitos: 
La unión de hecho en el Perú, los derechos de sus integrantes y desafíos pendientes The common law marriage in Peru, the rights of its members and pending challenges

- Cumplir con las condiciones consignadas en el artículo 326 del Código Civil.

- La convivencia debe encontrarse vigente al momento del fallecimiento de cualquiera de sus miembros.

- Las uniones de hecho deben estar inscritas en el Registro Personal, de conformidad con el art. 49 de la Ley 26662, o haber sido reconocidas por la vía judicial.

\subsection{Adopción}

La adopción es una institución social basada en una ficción legal, por la cual se establece una relación paterna o materna filial entre dos personas que no lo son por naturaleza, otorgándole los mismos derechos y deberes recíprocos entre padre e hijos o madre e hijos (Aguilar 2016, 338).

La Ley 30311 (promulgada el 16 de marzo de 2015) modifica los artículos 378 y 382 del Código Civil y reconoce el derecho a adoptar de los concubinos, teniendo como exigencia que dicha unión se encuentre inscrita en el Registro Personal de la Oficina Registral que corresponda al domicilio de los convivientes y que se cuente con el asentimiento de ambos.

Para que puedan acceder a este derecho se requieren ciertos requisitos entre los que encontramos: que los adoptantes gocen de solvencia moral, que la edad de cada adoptante sea por lo menos igual a la suma de la mayoridad y la del hijo por adoptar, que si el adoptado tiene más de 10 años preste su asentimiento, entre otros.

Antes de la dación de esta ley, solo podían adoptar los cónyuges por lo cual si una pareja de convivientes iniciaba el trámite de adopción se le exigía que, previamente, contraiga matrimonio ocasionando que se vulnere el derecho de los convivientes a integrar hijos a sus familias.

\subsection{Derecho a la Salud}

La Ley 26790 (Ley de la Modernización de la Seguridad Social en Salud) reconoce en su artículo 3 como derechohabientes al concubino a que se refiere el artículo 326 del Código Civil y la misma mención la hace su reglamento (D.S. N 009-97S.A.). Por otro lado, el actual Texto Único de Procedimientos Administrativos (TUPA) del Seguro Social de Salud - ESSALUD (Decreto Supremo N ${ }^{\circ}$ 14-2016-TR) establece como uno de los requisitos para el registro del concubino o concubina, la copia simple del documento de Reconocimiento de la Unión de Hecho, sea por Resolución Judicial o por Escritura Pública.

Con el TUPA anterior (D.S. $N^{\circ}$ 010-2010-TR) no se requería la Resolución Judicial o por Escritura Pública de Reconocimiento de Unión de Hecho sino que bastaba con la Declaración Jurada de relación de concubinato. Es preciso referir que, anteriormente, ESSALUD había emitido, a nivel de Resoluciones, disposiciones que implicaban la incorporación de este requisito; sin embargo, al ir contra el TUPA eran claramente ilegales. Incluso se llegó a plantear una Acción Popular (Sentencia A.P. $N^{\circ}$ 13619-2013 LIMA) contra una de esas resoluciones la cual fue declarada fundada y se declaró ilegal la resolución por ir contra el TUPA de ESSALUD vigente en ese entonces.

Con el nuevo TUPA, ESSALUD solo registra a los concubinos que han sido declarados judicialmente como tal o tienen su unión de hecho reconocida través de una Escritura Pública, lo cual perjudica a muchos concubinos que no han efectuado alguno de estos procedimientos y que son la mayoría, vulnerando el derecho a la salud y el derecho a la seguridad social reconocidos en nuestra Constitución. Asimismo, hace más burocrático el trámite que permite al conviviente gozar de un derecho humano fundamental, como es el derecho a la salud puesto que ya no basta la declaración jurada de su pareja, como era anteriormente sino que se debe realizar el procedimiento judicial o notarial previo, lo cual definitivamente es una barrera de acceso al derecho a la salud.

\section{Filiación Extramatrimonial}

Antes de la Constitución de 1979, todos los hijos nacidos producto de una convivencia eran considerados hijos ilegítimos, quienes incluso heredaban la mitad de lo que recibirían los hijos legítimos, hijos nacidos dentro de un 
matrimonio. Si los hijos eran concebidos por una pareja que no estaba casada y que no tenía impedimento matrimonial se les llamaban hijos naturales y si posteriormente, esta pareja se casaba, los hijos eran considerados legitimados desde la fecha del matrimonio de sus progenitores. Estos hijos legitimados tenían los mismos derechos de los hijos legítimos. Como vemos, existía discriminación entre los hijos, en cuanto a la denominación que nuestro ordenamiento les imponía, al recorte de sus derechos sucesorios y por supuesto, en cuanto a la determinación de una filiación extramatrimonial.

Actualmente, esa diferenciación ha quedado superado y todos los hijos tienen iguales e incluso está prohibida toda mención sobre el estado civil de los padres y sobre la naturaleza de la filiación. No obstante, si los convivientes procrean hijos nuestro ordenamiento lo regula como filiación extramatrimonial y una de las diferencias con la filiación matrimonial es que en esta se aplica la presunción pater is es decir, se presume que los hijos nacidos dentro de un matrimonio son hijos de los cónyuges. En el caso, de las uniones de hecho así estén inscritas en el registro personal no opera esta presunción de manera que, ambos padres deben reconocerlos voluntariamente ya sea en el registro de nacimiento, en escritura pública, en testamento o ante el juez, según lo regulado en el artículo 171 del Código de Niños y Adolescentes. Dicho acto es unilateral, no admite modalidad, es declarativo e irrevocable.

En caso contrario, se podrá iniciar un proceso de declaración judicial de filiación extramatrimonial, según lo regulado en el artículo 402 inciso 3 del Código Civil, entendiéndose la convivencia en sentido amplio (unión de hecho propia e impropia). La vía procedimental es una de conocimiento y debido a su complejidad podría acarrear que el derecho a la identidad de un niño o una niña quedará en suspenso por mucho tiempo.

Acorde a los avances tecnológicos y la premura que estos casos sean resueltos de una manera rápida y así garantizar el principio del interés superior del niño, se dio la Ley 28457 y sus posteriores modificatorias que regulan un proceso especial de declaración judicial de paternidad extramatrimonial que incorpora la prueba de ADN como el medio probatorio que acreditará de manera fehaciente un vínculo paterno filial. En este mismo juicio, se puede acumular la pretensión de alimentos para los hijos, el costo de la prueba de ADN debe ser asumido por el demandado y no es necesario el patrocinio de un abogado ni el pago de las tasas judiciales. Con lo cual, en caso de no existir un reconocimiento voluntario lo más recomendable es iniciar un proceso amparado en esta ley ya que es más célere que el anterior.

\section{Disolución de la unión de hecho}

La unión de hecho termina por muerte de uno de sus integrantes, ausencia regulada según el artículo 49 del Código Civil, por mutuo acuerdo, por decisión unilateral, por el matrimonio de ambos convivientes (pasarían de convivientes a cónyuges) o con el matrimonio de uno de los convivientes con otra persona.

Es preciso recordar que en el caso de decisión unilateral, cabe la posibilidad de que el juez conceda, a elección del abandonado, una indemnización o una pensión de alimentos. Por lo tanto, en algunos casos a pesar de que la unión de hecho puede estar disuelta, la pensión de alimentos para el ex conviviente puede seguir vigente incluso si el obligado a pasar la pensión contrae matrimonio visto que el artículo 316 inciso 2 señala que son cargas de la sociedad: "Los alimentos que uno de los cónyuges esté obligado por ley a dar a otras personas".

Por otro lado, es relevante establecer la fecha de inicio y de culminación de la unión de hecho con la finalidad de liquidar la sociedad de gananciales. En ese aspecto, es recomendable que exista un documento escrito de fecha cierta a fin de determinar desde cuándo concluye la unión de hecho y por consiguiente, desde cuándo los bienes adquiridos por los ex convivientes serán bienes propios.

\section{Unión de hecho homoafectivas}

A lo largo de este artículo hemos visto que las uniones de hecho han sido duramente tratadas y mal vistas con la consiguiente vulneración de derechos fundamentales a sus integrantes e incluso a sus hijos. Una situación similar es la que viene dándose 
La unión de hecho en el Perú, los derechos de sus integrantes y desafíos pendientes The common law marriage in Peru, the rights of its members and pending challenges

con las uniones homoafectivas, sabemos que existen, que son familia pero no cuentan con una protección normativa, a pesar que nuestra Constitución establece como principios y derechos fundamentales la dignidad y el derecho de igualdad y no discriminación parece que ello no es suficiente para que gocen de reconocimiento legal o de una justa protección a nivel judicial. Otra vez, cuestionamientos del sector conservador de nuestra sociedad ligada a la afectación de la moral y los valores católicos, vienen impidiendo que se efectivice el goce y ejercicio de sus derechos.

En ese sentido, coincidimos con Enrique Varsi cuando plantea lo siguiente:

"Cualquier país que pretenda ser democrático y guardián de los derechos humanos no puede tolerar la discriminación arbitraria, como es el caso de la discriminación de sexo o por orientación sexual. Lo contrario sería ir contra el criterio social (...). Los principios de dignidad, libertad e igualdad nos llevan a considerar que las relaciones homosexuales merecen una tutela al igual que las relaciones heterosexuales, en grado de paridad" (Varsi 2011, 429-430).

Lamentablemente, nuestro ordenamiento ha optado por negar la anuencia a las uniones homoafectivas a pesar de que han existido proyectos legislativos que han buscado otorgarles derechos, estos no se han concretado ni creando figuras distintas como son la unión civil, patrimonio compartido, atención mutua y el Régimen de Sociedad Solidaria ni incorporándolas dentro de la regulación de las uniones de hecho ni mucho menos permitiéndoles acceder al matrimonio. A pesar que, a nivel de Latinoamérica, países como Argentina, Uruguay o Colombia ya permiten, incluso, el matrimonio igualitario, nuestra conservadora sociedad sigue vulnerando los derechos de los miembros de las familias homosexuales, lo cual definitivamente es un tema pendiente y urgente.

Lo que nos queda por ahora es considerarlas como uniones de hecho impropias a consecuencia de que no cumplen con uno de los requisitos que es la intersexualidad debido a lo cual, la única posibilidad en caso de vulneración de sus derechos patrimoniales, en calidad de convivientes, sería la acción de enriquecimiento indebido, según lo regulado en el artículo 326 y los artículos 1954 y 1955 del Código Civil.

\section{Conclusiones}

Como vemos, el camino al reconocimiento de derechos a los integrantes de las uniones de hecho ha sido largo y accidentado y si bien han existido avances, notamos que aún quedan varios temas pendientes por resolver o de ser tratados, como son: la posibilidad de reclamar judicialmente una pensión de alimentos en uniones vigentes, la potestad de optar por un régimen de separación de patrimonios, el cambio normativo en cuanto a la pensión de viudez de los concubinos, la eliminación de barreras legales para el goce del derecho de salud, entre otros.

Finalmente, es trascendental y relevante que se reconozcan, a las uniones homoafectivas, la posibilidad de gozar de derechos personales y patrimoniales puesto que son fuente de familia y no podemos negar su existencia, vulnerar su dignidad, ni atentar contra el derecho a la igualdad que todos aspiramos como miembros de una sociedad democrática.

\section{Referencias bibliográficas}

Aguilar, Benjamín. 2016. Tratado de Derecho de Familia. $1^{\mathrm{a}}$ ed. Lima: Lex \& luris.

2017. Matrimonio y Filiación. Lima: Gaceta Jurídica.

Congreso de la República. 1997. Ley de Modernización de la Seguridad Social en Salud. http://www.essalud.gob.pe/transparencia/pdf/ publicacion/ley26790.pdf (consultada el 10 de noviembre de 2017).

2010. Ley $N^{\circ} 28457$ y modificatorias. Ley que regula el proceso de filiación judicial de paternidad extramatrimonial. https://pprfamilia.pj.gob.pe/wps/wcm/ connect/ 3 bd 7 d 9804875 ad 2 ab 212 
Erika Irene Zuta Vidal

b250d8336ffa/Ley+que+regula + el+ proceso+de+filiaci\%C3\%B3n+judicial+de+ paternidad+extramatrimonial.pdf? $\mathrm{MOD}=$ AJPERES\&CACHEID $=3 \mathrm{bd} 7 \mathrm{~d} 9804875 \mathrm{ad}$ 2ab212b250d8336ffa, http://busquedas. elperuano.com.pe/normaslegales/ley-quemodifica-el-proceso-de-filiacion-judicial-depaterni-ley-n-30628-1550559-1/ (consultada el 10 de setiembre de 2017).

2010. Ley $N^{\circ} 29560$ - Ley que amplía la Ley $\mathrm{N}^{\circ} 26662$, Ley de Competencia Notarial en Asuntos No Contenciosos, y la Ley $\mathrm{N}^{\circ} 26887$, Ley General de Sociedades. https://www.minjus. gob.pe/wp-content/uploads/2014/03/ley_29560. pdf (consultada el 1 de junio de 2017).

2013. Ley $N^{\circ} 30007$ - Ley que modifica los artículos 326, 724, 816 y 2030 del Código Civil, en el inciso 4 del artículo 425 y el artículo 831 del Código Procesal Civil y los artículos 35,38 y el inciso 4 del artículo 39 de la Ley 26662, a fin de reconocer derechos sucesorios entre los miembros de uniones de hecho. http:// busquedas.elperuano.com.pe/normaslegales/ ley-que-modifica-los-articulos-326-724816-y-2030-del-codi-ley-n-30007-925847-1/ (consultada el 10 de junio de 2017).

2015. Ley $N^{\circ} 30311$ - Ley que permite la adopción de menores de edad declarados judicialmente en abandono por parte de las parejas que conforman una unión de hecho. http://www.elperuano.com.pe/ NormasElperuano/2015/03/18/1213133-1.html (consultada el 10 de junio de 2017).

Plácido, Alex. 2001. Manual de Derecho de Familia. $1^{\text {a }}$ ed. Lima: Gaceta Jurídica.
2002. Regímenes patrimoniales del matrimonio y de las uniones de hecho en la doctrina y en la jurisprudencia. $1^{\text {a }}$ ed. Lima: Gaceta Jurídica.

Poder Judicial. 2014. Casación 1532-2013. https://scc.pj.gob. pe/wps/wcm/connect/5c8cd300469c660cb628ffac1e03f85e/ Resolucion+001532-2013+Patty.pdf?MOD=AJPERES \&CACHEID $=5 \mathrm{c} 8 \mathrm{~cd} 300469 \mathrm{c} 660 \mathrm{cb} 628 \mathrm{ffac} 1 \mathrm{e} 03 \mathrm{f} 85 \mathrm{e}$ (consultada el 15 de setiembre de 2017).

2015. Sentencia AP $N^{\circ} 13619$ - 2013. http://legis. pe/wp-content/uploads/2017/05/Sentencia-A.P.-N\%C2\%B013619-2013-Lima.pdf (Consulta: 10 de noviembre de 2017).

Presidencia de la República. 2016. Decreto Supremo N 014-2016-TR, Aprobación del Texto Único de Procedimientos Administrativos TUPA del Seguro Social de Salud ESSALUD. http://www.essalud.gob.pe/transparencia/pdf/tupa/ DS_014_2016_TR_TUPA_ESSALUD.pdf (consultada el $10 \mathrm{de}$ noviembre de 2017 ).

Reinoso, Martha. 1987. La Unión de Hecho. Análisis y perspectivas. Lima: Sin editorial.

Tribunal Constitucional. 2007. Sentencia del Caso Anaya Cruz (EXP. N ${ }^{\circ}$ 03605-2005-AA/TC). http://www.tc.gob.pe/ jurisprudencia/2007/03605-2005-AA.html (consultada el 1 de junio de 2017).

2007. Sentencia del Caso Rosas Domínguez (EXP. $\mathrm{N}^{\circ} \mathrm{TC}$ 06572-2006-PA/TC).

https://tc.gob.pe/jurisprudencia/2008/06572-2006-AA.pdf (consultada el 1 de junio de 2017).

Varsi, Enrique. 2011. Matrimonio y uniones estables. Tomo II de Tratado de Derecho de Familia. $1^{\text {a }}$ ed. Lima: Gaceta Jurídica. 


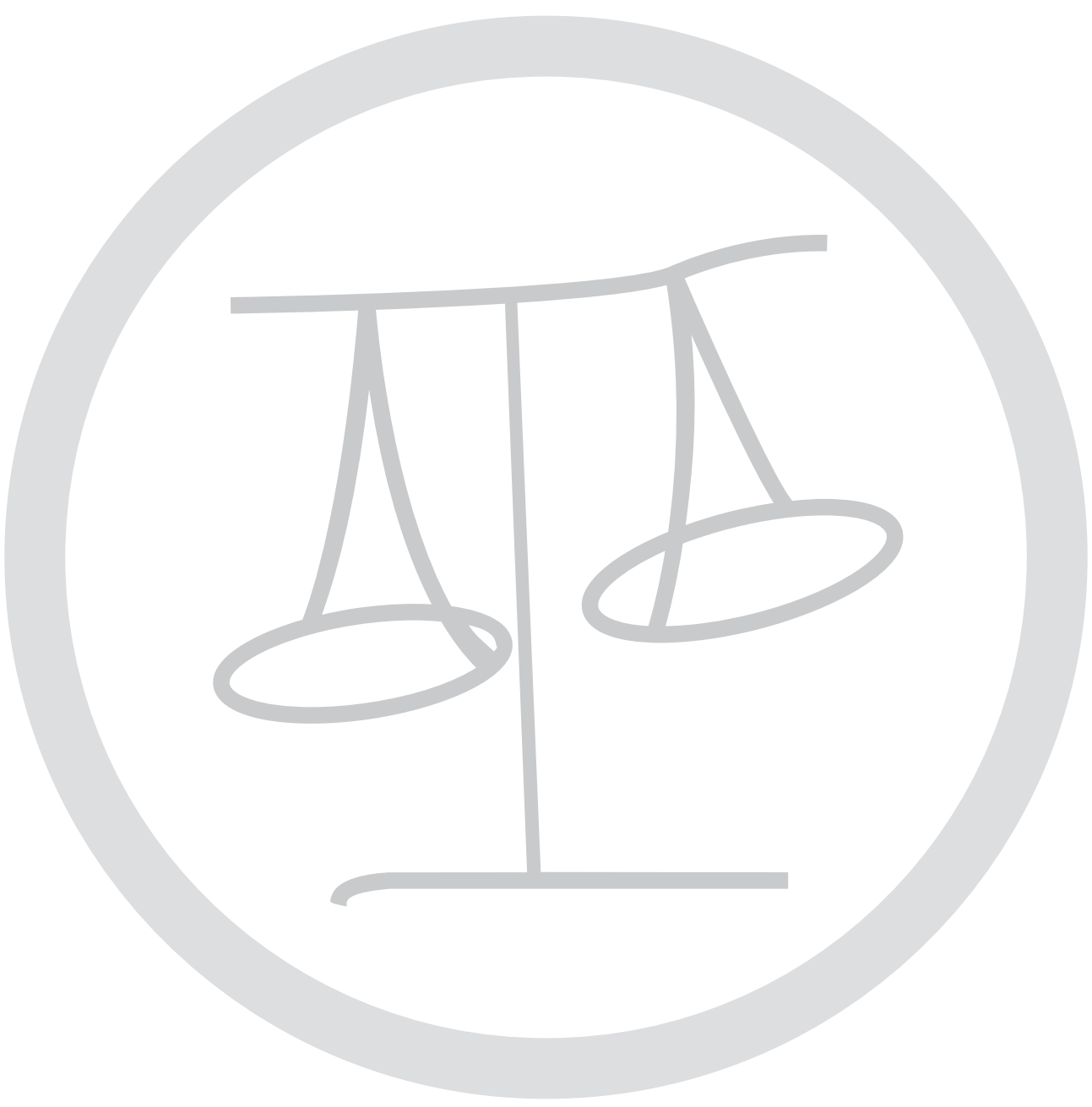

